\title{
A retrospective study of female breast cancer: Stage and age correlation
}

\author{
Akruwala S.D ${ }^{1}$, Sharma $V^{2}$ \\ ${ }^{1}$ Dr. Sushil Damodardas Akruwala, Associate Professor, Department of Surgery, GCSMCH \& RC, Ahmedabad, \\ ${ }^{2}$ Dr.Vidhyasagar M Sharma, Associate Professor, Department of Surgery, GCSMCH \& RC, Ahmedabad, Gujrat, India.
}

Corresspondence Author: Dr. Vidhyasagar M Sharma, Associate Professor, Department of Surgery, GCSMCH \& RC, Ahmedabad. E mail: sharma_vidhyasagar@yahoo.com Postal Address: Plot No.66, Shivshakti Industrial Estate, Kotarpur, Opp. Green Guest House, Airport Road, Near Noblenagar, Ahmedabad, Gujarat

\begin{abstract}
Background: With 1 million new cases in the world each year, breast cancer is the commonest malignancy in women and comprises $18 \%$ of all female cancers. At present carcinoma breast is the leading cancer in India and is competing cancer cervix in incidence. Epidemiological studies at regional and global levels suggest the occurrence of carcinoma breast at a younger, premenopausal age in Indian and Asian women as compared with western women. Knowledge of this factor emphasizes the need to modify the timing of modalities of detection of early carcinoma and its management. According to literature, majority of carcinoma breast cases in the western countries present in Stages I and II of the disease whereas in India majority cases present in Stage III of the disease. The objective of this study is to observe and study age correlation with female breast cancer. Methods: A retrospective study was conducted in 267 patients of histopathologically confirmed breast cancer. Results: Mean age of subjects was $44.34 \pm 8.55$ years. Age distribution showed peaks at 41-50 years with 134 patients. This study shows that $71.90 \%$ of the total patients were having advanced carcinoma breast (Stage III, IV) and $73.7 \%$ of these patients were below 50 years of age. Conclusions: Breast cancer is increasingly occurring in younger age groups in India when compared with western countries and a more aggressive nature of the disease strikes in their reproductive period suggesting the need for change in modalities of early cancer detection and adjusting preventive and therapeutic efforts.
\end{abstract}

Keywords: Breast, Carcinoma, age

\section{Introduction}

The most prevalent cancer in the world is breast cancer (4.4 million survivors upto 5 years following diagnosis) [1]. It is the most frequent cancer and cause of cancer deaths in females in developed and developing countries[1]. Breast cancer accounts for $23 \%$ of all newly occurring cancers in women world wide and represents $13.7 \%$ of all cancer deaths[1].

Breast cancer remains a leading dreadful cancer of women in India as well. Breast cancer has ranked number one cancer among Indian females with age adjusted rate as high as 25.8 per 100,000 women and mortality 12.7 per 100,000 women[2].Young age has been found as a major risk factor for breast cancer in Indian women[2]. Epidemiological studies at regional and global levels suggest that this cancer occurs at a

Manuscript Received: $14^{\text {th }}$ May 2018

Reviewed: $24^{\text {th }}$ May 2018

Author Corrected: $30^{\text {th }}$ May 2018

Accepted for Publication: $5^{\text {th }}$ June 2018 young premenopausal age in Indian and Asian women compared to western women who get it more than a decade or more later [3]. Studies suggest that the disease peaks at 40-50 years in Indian women [1]. The stage of disease at the time of reporting is worse in younger patients. Literature shows that in India majority of new cases are advanced stage- locally advanced or higher stage at the time of diagnosis [4]. According to various studies majority of carcinoma breast cases in the west report in Stages I and II of disease, whereas in India $45.7 \%$ report in advanced stages [3,5]. Asian countries may experience a potential breast cancer epidemic over the next decades as women adopt western lifestyles, marrying, and bearing children later in life, decreasing parity, shorter duration of breast feeding and change in dietary habits. Knowledge of all these factors means need to modify the modalities of detection of early carcinoma and its management so that the outcome of the disease is not compromised. 


\section{Original Research Article}

\section{Methods}

Place of study: Department of Surgery, GCS Medical College Hospital and Research Centre, Ahmedabad, Gujarat.

Type of study: Retrospective study

Period of study: From 2011 to 2017.

Sampling Method: Consecutive. Data were collected from both outpatient department and inpatient department. Data were collected using detailed proforma. A total of 267 patients were included in the study and their data regarding age, stage of disease, medical history, past history and family history were collected on a predesigned proforma.

Inclusion criteria: All the histopathologically confirmed female breast cancer cases during the said period were included.

Exclusion criteria: Those patients where detailed case reports were not available were excluded.

Statistical Analysis: All the relevant collected data was compiled on a master chart first then organized by scientific calculator and standard appropriate statistical formula. The results are presented in Tables.

\section{Results}

A total of 267 patients were treated for breast cancer in the 7-year period. Mean age of patients was $44.34 \pm 8.55$ years. Age distribution showed peak at 41-50 years. Number of patients below 50 years of age was 161 . Out of 267 patients 134 were between 40 and 50 years of age (Table 1). Number of patients in age groups 21-30, 31-40, 41-50, 51-60, >60 were $3,24,134,78$ and 28 respectively. Minimum age was 26 years and the maximum was 82 years and median age was 46 years.

Table-1: Distribution of breast cancer by age $(n=267)$.

\begin{tabular}{|c|c|c|}
\hline Age & Number of lesions & t (\%) $\mathbf{n = 2 6 7}$ \\
\hline $0-20$ years & -- & 1.12 \\
\hline $21-30$ years & 3 & 8.99 \\
\hline $31-40$ years & 24 & 50.18 \\
\hline $41-50$ years & 134 & 29.21 \\
\hline $51-60$ years & 78 & 10.48 \\
\hline$>60$ years & 28 & $267(100)$ \\
\hline Total & 267 & \\
\hline Mean \pm SD & $44.34 \pm 8.55$ & - \\
\hline
\end{tabular}

Out of 267 cases evaluated for presence of family history, 32 cases (11.98\%) revealed positive family history of cancer, among which breast or ovarian cancer were the commonest type (74.0\%). Patients below 40 years of age (27 patients) had more frequent occurrence of family history as compared to above 40 years. Of the total 267 patients 192 presented with advanced stage (Stages III and IV) of breast cancer. This study shows that $71.90 \%$ of the total patients were having advanced carcinoma breast (Stage III, IV) at the time of reporting and $73.7 \%$ of these patients were below 50 years of age (Table 2).

Table-2: Stage of breast cancer at presentation $(n=267)$.

\begin{tabular}{|c|c|c|}
\hline Stage & Number & Percentage \% \\
\hline Stage I & 18 & 6.74 \\
\hline Stage II & 57 & 21.34 \\
\hline Stage III & 130 & 48.68 \\
\hline Stage IV & 62 & 23.22 \\
\hline
\end{tabular}

\section{Discussion}

Breast cancer is the commonest cause of cancer death in women worldwide. Rates vary about five-fold around the world, but they are increasing in regions that until recently had low rates of the disease. 


\section{Original Research Article}

Many of the established risk factors are linked to oestrogens. Risk is increased by early menarche, late menopause, and obesity in postmenopausal women, and prospective studies have shown that high concentrations of endogenous oestradiol are associated with an increase in risk. Child bearing reduces risk, with greater protection for early first birth and a larger number of births; breastfeeding probably has a protective effect. Both oral contraceptives and hormonal therapy for menopause cause a small increase in breast-cancer risk, which appears to diminish once use stops. Alcohol increases risk, whereas physical activity is probably protective. Mutations in certain genes greatly increase breast cancer risk, but these account for a minority of cases.

Age is one of the most important risk factors for breast cancer. It is a common observation that risk of breast cancer increases with age. Median age of 46 years in the patients with breast cancer is much lower than median age seen in American population at 62 years [6].

The mean age of women with breast cancer in present study is 44.34 years, which is similar to study by Saxena et al in India where mean age is 47.8 years[7]. This mean age is also younger than seen in research on breast cancer elsewhere in developing countriesand a decade earlier than western women [7,8,9]. A study in India shows that there are two peaks in the age at diagnosis of breast cancer at 41-50 years and 51-60 years [10].

The latter peak is common with peak in western countries, but the peak at 41-50 years shows that the disease occurs at a younger age in Indian patients as compared to the west. Data of Delhi, India from 2001 to 2003 under national cancer registry program of ICMR recorded 529, 544, and 601 cases of breast cancer in age groups 40-44, 45-49, and 50-54 years respectively out of a total of 3777 breast cancer cases recorded[11].

In our study total $158 / 267(59.17 \%)$ patients belonged to age group 31-50 years. Similar results are observed in the study by Sandhu et al where a majority of the patients $(65.8 \%)$ were in the age group of $31-50$ years [12].

In our study family history of cancer particularly breast and ovarian cancer (74\%) was found in 32 cases $(11.98 \%)$ and most of these patients were below 40 years of age (27/32 patients). Similar results were found in study by Saxena et al where most of the patients with positive family history had age less than 45 years[7].
Well-established risk factors for breast carcinoma include age, ethnicity, family history of breast or ovarian cancer, age of menarche, age at menopause, age of first full term pregnancy [13]. Despite same risk factors the western population themselves do not have onset at younger ages, implying that there may be some genetic impact of Asian population to develop breast cancer earlier or there might be a role of environmental factors yet to be explored [14]

Therefore westernization may be responsible for increasing incidence of breast cancer, but may not be the reason for its occurrence in younger age groups[14]. Breast canceris a hormone dependent malignancy and the hormonal factors might be affecting Asian women differently who get menarche and menopause earlier in an average shorter life span compared with western women. However, all above factors only explain the increasing incidence of carcinoma breast but does not explain development of carcinoma in younger age.

Staging of the disease is essential particularly for estimating prognosis, planningtreatment, interpretation and comparison of outcome. According to various studies majority of carcinoma breast cases in the west report in Stages I and II of disease, whereas in India $45.7 \%$ report in advanced stages [3,5]. Similar results were observed in our study where $71.9 \%$ patients presented in Stages III and IV of disease.

Of these advanced cases of present study $73.7 \%$ patients were below 50 years of age confirming that the disease is more aggressive in younger patients. This study highlights the fact that in the population this malignancy is very aggressive and younger the age of getting this malignancy more aggressive is the disease. Delayed reporting with advanced carcinoma may be due to lack of awareness program, economic factors, social taboo, religious factors and paucity of health and medical facilities.

Screening programs that have been shown to be successful in Western countries cannot be implemented in a similar way in the country because the efficacy of mammographic screening might be questionable in populations with a different epidemiology of breast cancer regarding age, risk factors, and ethnicity. Limitation of this study is being limited number of patients studied in a tertiary level Hospital in Ahmedabad over a very brief period which may not be representative of whole country though gives an idea regarding the pattern. 


\section{Original Research Article}

\section{Conclusion}

Breast cancer occurrence has undergone an age shift. It presents at younger ages in Indian population with more advanced stage of cancer at presentation. A national cancer registry and large-scale population study may give a robust picture about the age of presentation and the stage at diagnosis of breast cancer. Thus this study brings light on the presenting stage of breast cancer which is advanced even at the comparatively young age. So it is the need of hour to focus on detecting breast cancer at an early stage as possible. This important epidemiological issue will influence the screening programs for breast cancer detection at early stage and alert women regarding various risk factors.

Author contribution : Both the authors were pioneer in designing the study and performa. First author collected the data and compiled it. He also analysed the collected data. The second author with the help of first author wrote down the entire study. The correspondence was handled and further corrections were made by the second author.

Conflict of interest: None declared.

Funding: Nil, Permission from IRB: Yes

Ethical approval: The study was approved by the Institutional Ethics Committee

\section{References}

1. Parkin DM, Bray F, Ferlay J, Pisani P. Estimating the world cancer burden: Globocan 2000. Int J Cancer. 2001 Oct 15; 94 (2):153-6.

2. Malvia S, Bagadi SA, Dubey US, Saxena S. Epidemiology of breast cancer in Indian women. DOI: 10.1111/ajco.12661

3. Kakarala M, Rozek L, Cote M, et al. cancer histology and receptor status characterization in Asian Indian and Pakistaniwomen in the U.S.--a SEER analysis. DOI:10.1186/1471-2407-10-191

4. Advani S. Partner profile: Cancer in India. INCTR News. 2004;5:18.
5. Leong SP, Shen ZZ, Liu TJ, et al. Is breast cancer the same disease in Asian and Western countries? DOI:10. 1007/s00268-010-0683-1

6. Anderson WF, Pfeiffer RM, Dores GM, Sherman ME. Comparison of age distribution patterns for different histopathologic types of breast carcinoma. Cancer Epidemiol Biomarkers Prev. 2006;15:1899-905. doi:10.1158/1055-9965. EPI-06-0191.

7. Saxena S, Rekhi B, Bansal A, Bagga A, Chintamani, Murthy NS. Clinico-morphological patterns of breast cancer including family history in a New Delhi hospital, India - A cross-sectional study. World J Surg Oncol. 2005; 3: 67.doi: 10.1186/1477-7819-3-67.

8. Anderson WF, Reiner AS, Matsuno RK, Pfeiffer RM. Shifting breast cancer trends in the United States. DOI: 10. 1200/JCO.2007.11.6079

9. Goel A, Bhan CM, Srivastava KN. Five yearclinico pathological study of breast cancer. Indian $\mathrm{J}$ Med Sci. 2003 Aug; 57 (8):347-9.

10. Chopra B, Kaur V, Singh K, Verma M, Singh S, Singh A. Age shift: Breast cancer is occurring in younger age groups - Is it true?. Clin Cancer Investig J. 2014; 3 :526-9.doi: 10.4103/2278-0513.142652.

11. National Cancer Registry Programme (ICMR). Consolidated Report of Population Based Cancer Registries 2001-2004. Individual Registry Data. 2001$2003 ; 161$.

12. Sandhu DS, Sandhu S, Karwasra RK, Marwah S. Profile of breast cancer patients at a tertiary care hospital in north India. DOI:10.4103/0019-509X.58853

13. Hulvat MC, Hansen NM, Jeruss JS. Multidisciplinary care for patients with breast cancer. DOI: 10. 1016/j.suc.2008.10.002

14. Chauhan A, Subba SH, Menezes RG, et al. Younger women are affected by breast cancer in South India - a hospital-based descriptive study. Asian Pac J Cancer Prev. 2011;12(3):709-11.

\section{How to cite this article?}

Akruwala S.D, Sharma V. A retrospective study of female breast cancer: Stage and age correlation. Surgical Update: Int J surg Orthopedics. 2018;4 (2): 71-74.doi:10.17511/ijoso.2018.i02.02. 